\section{Female Sex Offenders}

SIR: In O'Connor's interesting account of female sex offenders (Journal, May 1987, 150, 615-620), one example stands out and cannot go unremarked.

Case 6 is that of a young woman and her 3-yearold daughter who, after parting from an alcoholic and violent husband and father, were living with an affectionate man whom the mother was about to marry. The "offence" consisted of the man on one occasion allowing the child to hold his penis, with the mother's agreement. Intercourse between the couple had at times occurred, as probably in many families, in the small child's presence.

The result of these events was, not that counselling was offered to the parents, but that the mother and her cohabitee were imprisoned for two and three years, respectively, thereby presumably leaving the child parentless. It seems the mother had been seen by a psychiatrist (not the author) at the time of the trial and "No psychiatric abnormality was found ...".

O'Connor could have helped us greatly by indicating the steps taken by the first psychiatrist to support this family and prevent the Court from depriving a child, at a vulnerable developmental stage, of her parents, when these were apparently affectionate and cared both for her and each other. Some discussion of how the sexual behaviour within this family came to be discovered, and defined as an "offence", would also have been of interest.

University of Edinburgh Department of Pula WolF Royal Edinburgh Hospital

Morningside Park

Edinburgh EHIO SHF

SIR: The woman involved (Mrs C) sometimes looked after a neighbour's children. Mrs C's child told these children what had happened and they told their mother, the neighbour. She in turn informed the NSPCC, and they informed the police and social services.

Mrs C and her co-defendant were both remanded on bail for the six months before the case came to Crown Court. The child was taken into foster care and Mrs C saw her twice weekly.

Mrs C, her co-defendant, and the child were assessed on one occasion while on bail by a child psychiatry team experienced in child sexual abuse cases. In their report they expressed a willingness to continue seeing them should the parents be at liberty, but they expressed serious reservations about the child being returned to $\mathrm{Mrs} \mathrm{C}$ if her co-defendant was living in the same house until a long period had elapsed.
At Crown Court Mrs C and her co-defendant pleaded guilty and were both remanded in custody for the preparation of reports. At time of sentencing, the report of the child psychiatry team, a probation report, and a psychiatric report were all available to the Court.

I too was surprised by the sentence in this case.

Friern Hospital

ART O'CONNOR

Friern Barnet Road

London NII 3BP

\section{Comparative Trial of a New Antidepressant}

SIR: The trial by Levine et al (Journal, May 1987, 150, 653-655) had a "double blind" design. However, tremor was four times more common with fluoxetine than with imipramine $(P<0.01)$. Does it not occur to the authors that this may have undermined the double-blind design? A notional double-blind design may be subverted by side-effects. This possibility may be addressed empirically by inviting participants to guess the patients' drug status on each occasion when drug effects are being assessed; observed guesses can then be compared statistically with those to be expected by chance, thereby providing a measure of how "double-blind" the study is.

Hesketh Park Hospital

M. L. RoBINSON Southport

Merseyside PR9 OLT

SIR: It is theoretically possible to undermine the double-blind design of clinical trials when there is a significant difference in response between the trial and comparator drugs. This can be either a measurable or easily-detected difference in clinical efficacy or in the side-effect profile.

It has been an unfulfilled ambition of mine to carry out a clinical study when the former occurred in favour of the new compound. In this study a significant difference was elicited with one minor side-effect which did not influence compliance, and little attention was paid to this effect until the results were analysed.

Clearly it would be possible to attempt to break a double-blind design if the difference were obvious. As this is not the intention of double-blind studies I can see little advantage being gained by attempting to break the code in advance of completing the trial. If there is any advantage in doing so I am sure that there would be many such studies where this might be more easily accomplished.

Oldham \& District General Hospital

SidNey LeVINE

Rochdale Road

Oldham OLI $2 \mathrm{JH}$ 